\title{
Neuropathic ankle fractures
}

\author{
Allison Tucker, BKin (Hons)*; N. Craig Stone, MD, MSc*
}

\section{ABSTRACT}

A 65-year-old diabetic female presented with a 3-week history of a left swollen foot after a minor inversion injury and was found to have a minimally displaced fibular fracture. Despite casting and strict instructions to remain non-weight bearing, the patient continued to bear weight and later developed a significantly more displaced fracture with a draining ulcer. This injury eventually required a tibiotalocalcaneal arthrodesis using a retrograde hindfoot nail. Neuropathy and neuropathic fractures can be devastating complications of diabetes and thus require early diagnosis and intervention because they may result in significant morbidity for the patient. Thorough assessment involving imaging, a complete history and physical examination, and tools such as a $129 \mathrm{~Hz}$ tuning fork and the $10 \mathrm{~g}$ SemmesWeinstein monofilament are paramount to establishing an accurate initial diagnosis. These tactics aid in future followup of the patient's injury and can be employed in both the clinic and the emergency department. Although management remains controversial for neuropathic ankle fractures because both conservative and surgical treatment regimens have high complication rates, open reduction and internal fixation continues to be the treatment of choice once closed reduction has been attempted and fails. Education is essential because diabetic patients have compromised pain and pressure sensation, which can lead to injuries and subsequent complications of which they are simply unaware. Physicians must be diligent when evaluating the diabetic foot and be explicit when providing instructions to these patients because preventing these injuries and their complications is the best patient care available.

\section{RÉSUMÉ}

Une femme diabétique de 65 ans présentait un historique de 3 semaines d'enflure du pied gauche après une inversion mineure. Une fracture du péroné minimalement déplacée lui a été diagnostiquée. Malgré un plâtre et la recommandation formelle de ne pas s'appuyer sur son pied, la patiente a continué de mettre du poids sur son pied et a par la suite développé une fracture significativement plus déplacée, avec ulcère suintant. Cette blessure a fini par exiger une arthrodèse tibiotalocalcanéenne avec utilisation d'un clou de manière rétrograde dans I'arrière-pied. Les neuropathies et les fractures neuropathiques peuvent constituer de graves complications du diabète et nécessitent donc un diagnostic et une intervention précoces, puisqu'elles peuvent entraîner une morbidité significative pour le patient. Une évaluation approfondie incluant de l'imagerie, un historique et un examen physique complets, ainsi que des outils tels qu'un diapason de $129 \mathrm{~Hz}$ et le monofilament Semmes-Weinstein $10 \mathrm{~g}$ sont cruciaux dans l'établissement d'un diagnostic précoce exact. Ces tactiques favorisent le suivi futur de la blessure du patient et peuvent être utilisées à la clinique comme au service des urgences. Même si la gestion des fractures neuropathiques de la cheville demeure controversée à cause du taux élevé de complications pour les traitements chirurgicaux tout comme pour les traitements plus conservateurs, la fixation continue d'être le traitement de choix une fois qu'une réduction orthopédique a été tentée et a échoué. Il est essentiel de faire de la prévention puisque les patients diabétiques voient leur perception de la douleur et de la pression affectée, ce qui peut entraîner des blessures et des complications subséquentes desquelles ils ne sont simplement pas conscients. Les médecins doivent faire preuve de diligence lorsqu'ils évaluent le pied diabétique et être explicites lorsqu'ils donnent des consignes à ces patients; en effet, prévenir ces blessures et leurs complications est le meilleur soin qu'on puisse offrir aux patients.

Keywords: ankle, diabetes, fracture, neuropathic

According to the Canadian Diabetes Association, an estimated 246 million people worldwide suffer from diabetes mellitus, including 2 million Canadians. Diabetes is currently the fourth leading cause of death worldwide, and, sadly, the number of people affected is rising and is expected to reach 366 million globally by 2030. ${ }^{1}$

Diabetes is a systemic disease that affects most systems in the body, including the musculoskeletal

From the *Division of Orthopedic Surgery, Memorial University, St. John's, NL.

Correspondence to: Dr. N. Craig Stone, 71 Carpasian Road, St. John's, NL A1B 2R6; stone@nf.sympatico.ca.

Submitted January 20, 2010; Revised July 27, 2010; Accepted August 6, 2010. 
system. Diabetics are at increased risk for bone disease, including fragility fractures, vasculopathy, and neuropathy, which can sometimes lead to neuropathic fractures. Neuropathic fractures occur in areas of reduced sensation secondary to diseases such as diabetes and result from chronic destruction of the bones and joints. Early diagnosis and patient education are critical in the prevention of such complications, and it is essential that all health care team members are vigilant with their assessment and follow-up. The following case report describes a diabetic patient who suffered from such a devastating fracture and discusses the unique diagnostic process, management, and potential complications associated with this patient population.

\section{CASE REPORT}

A 65-year-old female household ambulator presented with a 3-week history of a swollen left ankle. The swelling began after a minor ankle inversion injury. The patient did not fall but heard an audible snap, and the ankle became immediately swollen. She continued to ambulate postinjury without pain.

There was a long past medical history of poorly controlled type 2 diabetes mellitus with evidence of end-organ damage that included retinopathy, renal insufficiency, and peripheral neuropathy leading to a forefoot ulceration. On physical examination 3 weeks postinjury, she had a well-aligned but very swollen ankle. Initial radiographs revealed a minimally displaced fibular fracture (Figure 1).

She was placed in a well-padded cast and instructed to remain non-weight bearing. One week later, she returned with continued swelling and radiographs were obtained (Figure 2).

There continued to be no discomfort. Her cast was soft on the sole, and she confessed to some weight bearing. She refused to be admitted to hospital for treatment and was recasted. She returned 1 week later with more deformity and a draining ulcer over the medial malleolus (Figure 3 and Figure 4).

She finally agreed to hospital admission. Unfortunately, despite 2 weeks of intravenous antibiotics and splinting, her medial ulcer and the associated cellulitis did not improve. Therefore, it was felt that surgical intervention was required. Owing to poor bone quality, an unreconstructable tibial plafond, and probable deep infection, a hindfoot arthrodesis was deemed the best surgical approach.

A tibiotalocalcaneal arthrodesis was performed with a retrograde hindfoot nail. She was kept non-weight bearing as an inpatient for 3 months. The ulcer settled,
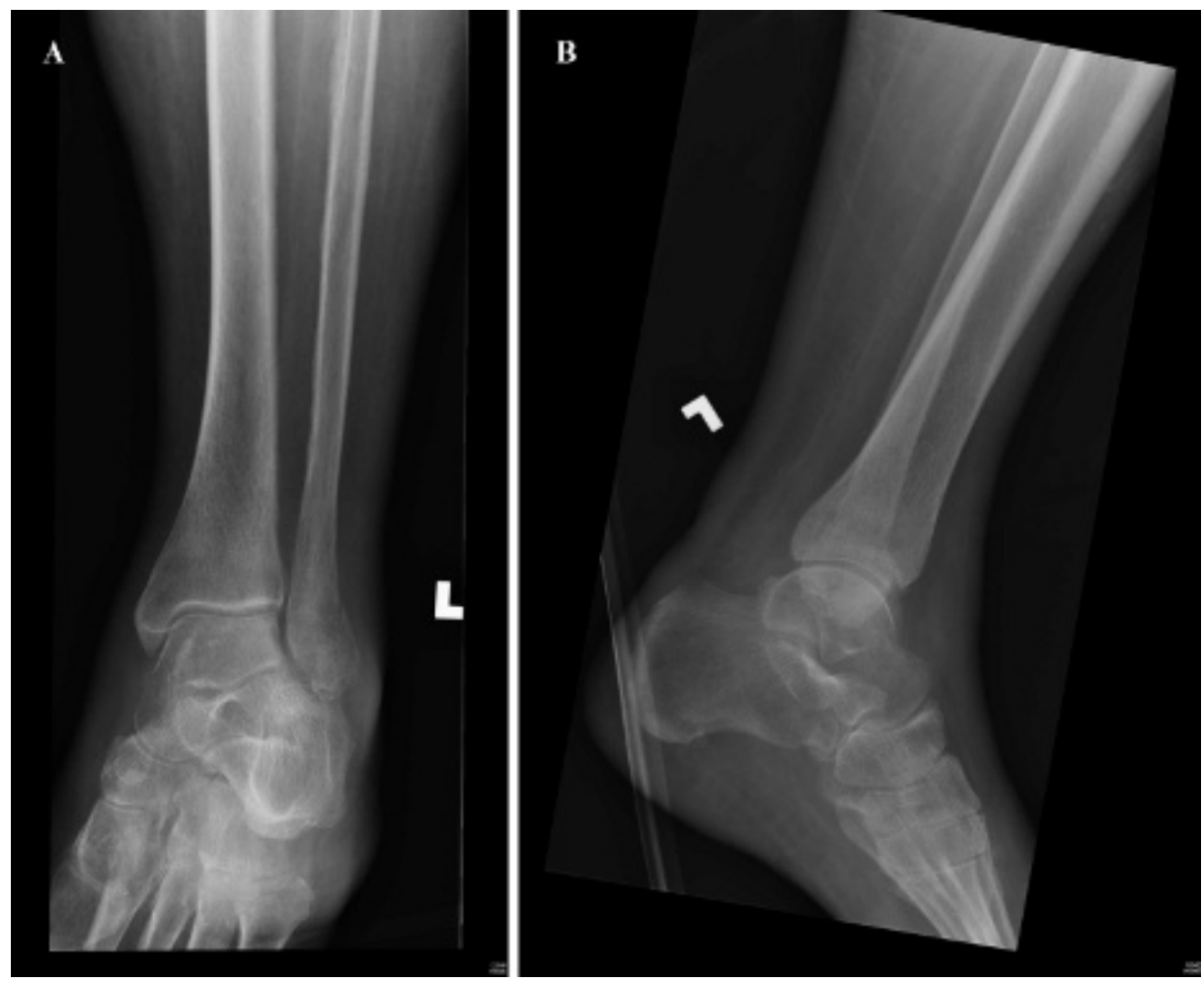

Figure 1. Anteroposterior (A) and lateral (B) radiographs 3 weeks postinjury, demonstrating a minimally displaced lateral malleolus fracture and no subluxation of the ankle mortice. Note that there is no obvious presence of a medical malleolar fracture. 

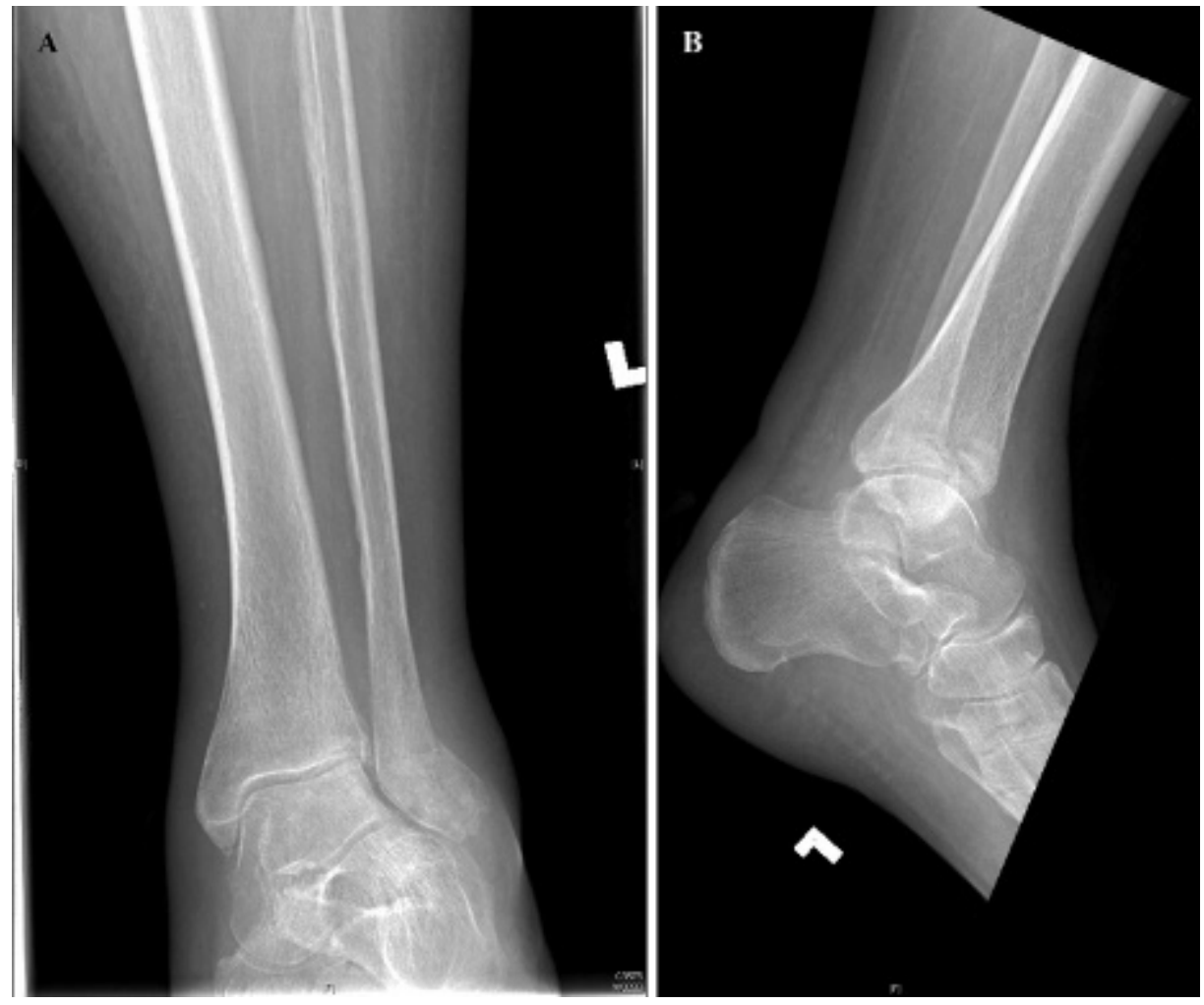

Figure 2. Anteroposterior (A) and lateral $(B)$ radiographs 4 weeks postinjury. Note the displacement of the fibular fracture and some impaction of the anterior lateral tibial plafond. There is a subtle line through the medial malleolus, likely representing an undisplaced fracture.

and she began to ambulate with a walker. She has returned to her status as a household ambulator.

\section{DISCUSSION}

Diabetics are at a high risk for bone disease owing to decreased unmineralized bone matrix, hypercalciuria, elevated collagen glycosylation, and a low rate of bone turnover with decreased bone formation and resorption. Consequently, these patients have decreased bone density, thus placing them at risk for fragility fractures. ${ }^{2}$ In addition, vascular disease is common as arteriosclerosis is seen more frequently in diabetics and its manifestations are more aggressive and diffuse compared to those of nondiabetics. Macrovascular disease causes calcification of the tunica media, which leads to the "lead pipe" appearance of the arteries in the distal limbs, thereby predisposing patients to peripheral vascular insufficiency. ${ }^{1}$

Neuropathy is a common manifestation of diabetes mellitus, causing irreversible and progressive damage to the sensory, motor, and autonomic nervous systems. ${ }^{1,3,4} \mathrm{Up}$ to $40 \%$ of diabetic patients will be diagnosed with peripheral neuropathy within the first 10 years of their disease, and $80 \%$ of diabetics with foot ulcers suffer from neuropathy. 5,6 Neuropathy results in decreased pain and pressure perception, leading to muscle imbalance and anatomic deformities, as well as impairment of the skin's integrity and dysfunction of the microcirculation. In the early stages, there is evidence of disruption of the articular cartilage and ligaments and eburnation and resorption of bone, in addition to the formation of osteophytes, periosteal bone, and loose bodies.?

Neuropathic arthropathy, which is often referred to as Charcot arthropathy, is a noninfectious, destructive process that results in eventual joint dislocation and periarticular fracture. It is a common complication of conditions that alter sensation, such as diabetes mellitus. Light touch and pain sensation are frequently affected, whereas motor function remains intact; therefore, these patients are at risk for injury owing to their inability to perceive joint overload or trauma. ${ }^{3,6}$ Charcot arthropathy generally presents with a warm, edematous, erythematous limb that may or may not be painful. Radiologic findings range from microfractures to bone fragmentation to severe joint subluxation and deformity. ${ }^{5,6,8}$

Although neuropathy is common in diabetic patients, neuropathic fractures occur surprisingly less often, with an incidence of only 1 to $2.5 \%$. However, they can be devastating when they occur owing to the 

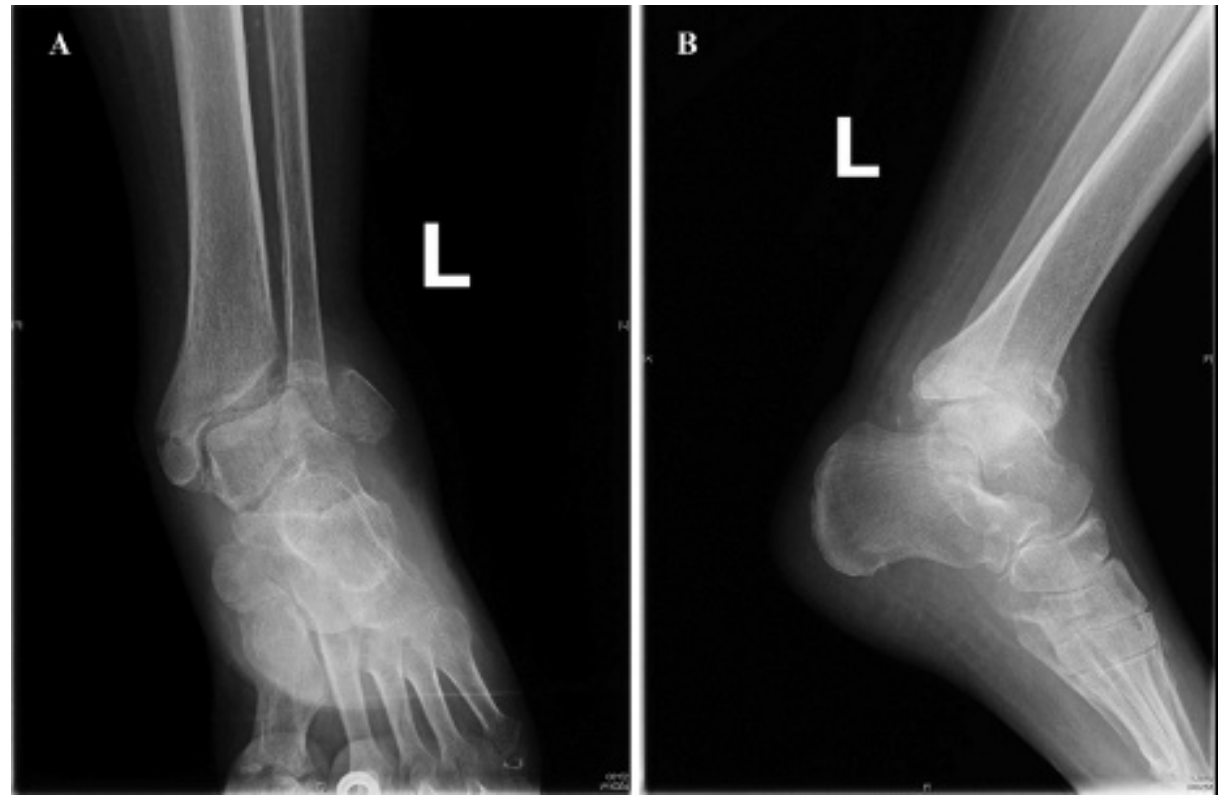

Figure 3. Anteroposterior (A) and lateral $(B)$ radiographs 5 weeks postinjury that show severe displacement of both the lateral and medical malleolar fractures. There is further impaction of the tibial plafond with anterior lateral subluxation of the talus.

high incidence of complications such as impaired wound healing, infection, and malunion or nonunion. ${ }^{79}$ Neuropathic fractures occur as a result of decreased sensation combined with normal motor function and active use; thus, they can occur in the acute setting or as a consequence of overuse. ${ }^{7}$

Assessment of the diabetic foot involves a comprehensive history and physical examination that includes both neurologic and vascular assessments. A $129 \mathrm{~Hz}$ tuning fork and the $10 \mathrm{~g}$ Semmes-Weinstein monofilament are two noninvasive, inexpensive, and relatively reliable methods for screening patients for neuropathy.

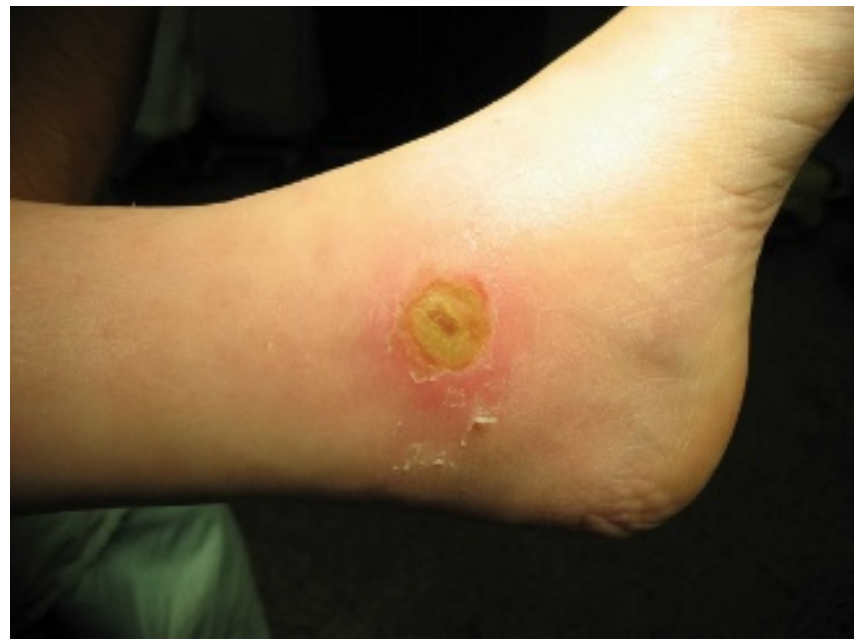

Figure 4. Medial ulceration secondary to skin pressure from the displaced medial malleolar fracture and subluxation of the ankle.
Although the use of these tools is encouraged, it may not be realistic for many emergency physicians; therefore, palpation of peripheral pulses remains the foundation of the vascular evaluation. It should be noted that the ankle/brachial pressure is frequently unreliable in patients with diabetes. ${ }^{6}$ Light touch, vibration sense, temperature distinction, and two-point discrimination tests can be used as quick methods for assessing a patient for sensory deficits. ${ }^{710}$ Radiographs should be obtained with the patient weight bearing if possible because these films provide a more accurate anatomic assessment of the functional stability of the ankle joint that may not be as evident on non-weight-bearing films. ${ }^{6}$ Findings often demonstrate either an atrophic process with bone resorption or a hypertrophic process with periarticular bone and osteophyte formation. ${ }^{7}$

The treatment of neuropathic ankle fractures remains controversial because complication rates remain high with both conservative and surgical treatment regimens. Open reduction and internal fixation (ORIF) continues to be the treatment of choice when closed reduction attempts fail, despite the increased risk of postoperative complications. These complications are especially high in patients whose treatment has been delayed, who have other comorbid conditions, or who abuse drugs or alcohol. ${ }^{3}$ The most recent literature advocates surgical intervention with increased immobilization periods for medically stable diabetic patients who have displaced fractures because these patients are at risk for developing Charcot 
arthropathy and ulcerations. ${ }^{11}$ The mainstay in treatment for Charcot arthropathy remains extended immobilization and non-weight bearing in a cast or brace. ${ }^{10}$ This conservative, nonoperative treatment places the patient at a significant risk for developing wound complications, which are difficult to treat and may further compromise the healing potential and the integrity of the joint in diabetics. ${ }^{10,11}$ However, because complication rates for surgical procedures can be as high as $47 \%$, it may be advantageous to forgo operative intervention for noninvasive treatments such as extended immobilization and elevation. These conservative options may be especially beneficial for certain populations such as low-demand and elderly patients, whose malunions may be an acceptable result. $^{8}$

Complications from both conservative and operative treatment of ankle fractures are consistently higher in diabetic patients, especially those who have longstanding disease and are insulin dependent. ${ }^{11,12}$ Significant risk factors for complications also include peripheral vascular disease, which may be indicated by absent pedal pulses, as well as peripheral neuropathy. These factors may predispose the patient to developing Charcot arthropathy. ${ }^{11,12}$ Complications include both superficial and deep infections, hardware failures, reflex sympathetic dystrophy, wound dehiscence, ulcerations, delayed fracture healing, malunions, nonunions, and Charcot arthropathy. ${ }^{7,-9,13,14}$ These potential complications must be taken into consideration when determining a treatment plan for the diabetic patient with a neuropathic ankle fracture. ${ }^{6}$

\section{CONCLUSION}

Peripheral neuropathy is a serious complication of diabetes that places patients at an increased risk for neuropathic fractures and complications from these fractures secondary to decreased pain and pressure perception. Although the treatment of neuropathic ankle fractures remains controversial, it is evident that early diagnosis and intervention, whether conservative or surgical, remain the key. It is imperative to prevent progressive complications from continued weight bearing, as was demonstrated in this case. Prevention of the initial neuropathy and later neuropathic fractures should remain the goal of patient care. This can be accomplished through education about the importance of tight glucose control and thorough foot care. Use of the tools, techniques, and appropriate imaging discussed above can aid the emergency physician in making an accurate, initial diagnosis, which may help prevent the devastating complications that were seen in this patient.

Competing interests: None declared.

\section{REFERENCES}

1. Robinson AHN, Pasapula C, Brodsky JW. Surgical aspects of the diabetic foot. 7 Bone Foint Surg Br 2009;91-B:1-7.

2. Hordon LD, Nathan DM, Drezner MK, et al. Bone disease in diabetes mellitus. Available at: http://www.uptodate.com/ contents/bone-disease-in-diabetes-mellitus (accessed August 5, 2011).

3. Gainor BJ. Disorders of nerves. In: Greene WB, editor. Netter's orthopedics. Philadelphia: Saunders Elsevier; 2006. p. 138-41.

4. Stone NC, Daniels TR. Midfoot and hindfoot arthrodeses in diabetic Charcot arthropathy. Can 7 Surg 2000;43:449-55.

5. McCulloch DK, Nathan DM, Mulder JE. Evaluation of the diabetic foot. Available at: http://www.uptodate.com/contents/ evaluation-of-the-diabetic-foot (accessed August 5, 2011).

6. Thordarson DB. Foot and ankle. Chicago: Lippincott, Williams; 2004.

7. Myerson MS, Edwards WHB. Management of neuropathic fractures in the foot and ankle. 7 Am Acad Orthop Surg 1999; 7:8-18.

8. Bibbo C, Lin SS, Beam HA, et al. Complications of ankle fractures in diabetic patients. Foot Ankle Trauma 2002;32: 113-33.

9. Chaudhary SB, Liporace FA, Gandhi A, et al. Complications of ankle fracture in patients with diabetes. 7 Am Acad Orthop Surg 2008;16:159-69.

10. Ayoub MA. Ankle fractures in diabetic neuropathic arthropathy - can tibiotalar arthrodeses salvage the limb? 7 Bone Foint Surg Br 2008;90-B:906-14.

11. Costigan W, Thordarson DB, Debnath UK. Operative management of ankle fractures in patients with diabetes mellitus. Foot Ankle Int 2007;28:32-7, doi:10.3113/ FAI.2007.0006.

12. Flynn JM, Rodriguez-del Rio F, Pizá PA. Closed ankle fractures in the diabetic patient. Foot Ankle Int 2000;21: 311-9.

13. Blotter RH, Connolly E, Wasan A, et al. Acute complications in the operative treatment of isolated ankle fractures in patients with diabetes mellitus. Foot Ankle Int 1999;20:687-94.

14. Wukich DK, Kline AJ. The management of ankle fractures in patients with diabetes. 7 Bone foint Surg Am 2008;90-A: 1570-8. 